\title{
Effects of Grazing Exclusion on Soil Carbon and Nitrogen Storage in Semi-arid Grassland in Inner Mongolia, China
}

\author{
WU Xing ${ }^{1,2}$, LI Zongshan ${ }^{1}$, FU Bojie ${ }^{1}$, LU Fei ${ }^{1}$, WANG Dongbo ${ }^{3}$, LIU Huifeng ${ }^{1}$, LIU Guohua ${ }^{1}$ \\ (1. State Key Laboratory of Urban and Regional Ecology, Research Center for Eco-Environmental Sciences, Chinese Academy of Sci- \\ ences, Beijing 100085, China; 2. State Key Laboratory of Forest and Soil Ecology, Institute of Applied Ecology, Chinese Academy of \\ Sciences, Shenyang 110164, China; 3. Environmental Monitoring Center of Hulun Buir, Hulun Buir 021008, China)
}

\begin{abstract}
The semi-arid grasslands in Inner Mongolia, China have been degraded by long-term grazing. A series of ecological restoration strategies have been implemented to improve grassland service. However, little is known about the effect of these ecological restoration practices on soil carbon and nitrogen storage. In this study, characteristics of vegetation and soil properties under continued grazing and exclusion of livestock for six years due to a nationwide conservation program-'Returning Grazing Lands to Grasslands (RGLG)' were examined in semi-arid Hulun Buir grassland in Inner Mongolia, China. The results show that removal of grazing for six years resulted in a significant recovery in vegetation with higher above and below-ground biomass, but a lower soil bulk density and $\mathrm{pH}$ value. After six years of grazing exclusion, soil organic $\mathrm{C}$ and total $\mathrm{N}$ storage increased by $13.9 \%$ and $17.1 \%$, respectively, which could be partly explained by decreased loss and increased input of $\mathrm{C}$ and $\mathrm{N}$ to soil. The effects of grazing exclusion on soil $\mathrm{C}$ and $\mathrm{N}$ concentration and storage primarily occurred in the upper soil depths. The results indicate that removal of grazing pressure within the RGLG program was an effective restoration approach to control grassland degradation in this region. However, more comprehensive studies are needed to evaluate the effectiveness of the RGLG program and to improve the management strategies for grassland restoration in this area.
\end{abstract}

Keywords: grazing exclusion; soil carbon storage; soil nitrogen storage; grassland management; Returning Grazing Lands to Grasslands (RGLG) program; semi-arid grassland; Hulun Buir grassland

Citation: Wu Xing, Li Zongshan, Fu Bojie, Lu Fei, Wang Dongbo, Liu Huifeng, Liu Guohua, 2014. Effects of grazing exclusion on soil carbon and nitrogen storage in semi-arid grassland in Inner Mongolia, China. Chinese Geographical Science, 24(4): 479-487. doi: $10.1007 / \mathrm{s} 11769-014-0694-1$

\section{Introduction}

With the increase in atmospheric carbon dioxide, extensive work has been conducted to improve our understanding of global carbon and nitrogen cycles and identify the possibility of various potential carbon sinks. Soil is the largest organic $\mathrm{C}$ reservoir in the terrestrial biosphere, storing more than twice the amount of carbon than the vegetation or the atmosphere (Lal, 2004; Wang et al., 2011; Liu et al., 2013). Grasslands cover approximately $25 \%$ of the terrestrial surface and play a critical role in the global $\mathrm{C}$ and $\mathrm{N}$ cycles and storage (Lal, 2004; Cui et al., 2005; Wu et al., 2013). On a global scale, grasslands store $10 \%-30 \%$ of global soil organic carbon (SOC) and have been estimated to sequester $\mathrm{C}$ in soil at a rate of $0.5 \mathrm{Pg} \mathrm{C} / \mathrm{yr}$, which is about one-fourth of the potential $\mathrm{C}$ sequestration in the world soils (Follett and Reed, 2010; Qiu et al., 2013). However, grazing by domestic livestock, one of the major human activities in grassland around the world, has been found to have significant effects on $\mathrm{C}$ and $\mathrm{N}$ cycles and storage (Cui et al., 2005; Su et al., 2005; Klumpp et al.,

Received date: 2013-10-30; accepted date: 2014-02-27

Foundation item: Under the auspices of Strategic Priority Research Program of Chinese Academy of Sciences (No. XDA05060103),

National Natural Science Foundation of China (No. 41105117), State Key Laboratory of Forest and Soil Ecology (No. LFSE2013-06)

Corresponding author: LIU Guohua. E-mail: ghliu@rcees.ac.cn

(C) Science Press, Northeast Institute of Geography and Agroecology, CAS and Springer-Verlag Berlin Heidelberg 2014 
2009; Mcsherry and Ritchie, 2013).

Approximate $40 \%$ of the total land area in China was covered by grasslands, which account for about $6 \%-8 \%$ of the total world grassland area and contain $9 \%-16 \%$ of the world's total grassland carbon stocks $(\mathrm{Ni}, 2002)$. However, by the end of the 20th century, most of these grasslands were degraded as a consequence of a rapid expansion in livestock numbers and economic reforms initiated in the late 1970s, especially for the semi-arid grasslands in Inner Mongolia (Chen and Wang, 2000; He et al., 2008; Wu et al., 2010). Thereafter improved grassland management strategies have been implemented with the aim to control grassland degradation. Especially, a nationwide conservation program - 'Returning Grazing Lands to Grasslands (RGLG)' was launched by the Chinese government in 2003. Grazing exclusion, which has been extensively employed throughout the world to improve grassland service, was one of most common practices for grassland restoration in this program. In recent years, intensive studies concerning the effects of grazing exclusion on vegetation succession and community structure have been conducted (Wu et al., 2009; Cheng et al., 2011; He et al., 2011), whereas only a few studies were focused on its effects on soil carbon and nitrogen storage in semi-arid grassland of Inner Mongolia, particularly referring to the RGLG program. Although there is a growing number of studies pointing out that grazing exclusion could increase the storage of soil C and N (Cui et al., 2005; He et al., 2008; Qiu et al., 2013), some other studies have shown that grazing exclusion has no impact on soil $\mathrm{C}$ storage (Shrestha and Stahl, 2008; Medina-Roldan et al., 2012) or even cause a reduction in soil $\mathrm{C}$ and $\mathrm{N}$ storage (Reeder et al., 2004; Liu et al., 2012). Therefore, understanding the dynamics of soil $\mathrm{C}$ and $\mathrm{N}$ storage following grazing exclusion is essential to evaluate the benefit of the RGLG program and to improve the management practices for grassland restoration.

In this study, we investigated the changes in soil organic carbon and total nitrogen (TN) storage and other characteristics of three fenced sites relative to the paired adjacent grazed sites in the Hulun Buir grassland of Inner Mongolia, China. The main objectives of this study were to better understand the mechanisms of effects of grazing exclusion on soil $\mathrm{C}$ and $\mathrm{N}$ storage in semi-arid grasslands in the northern China, and to assess whether the RGLG program could advance soil $\mathrm{C}$ and $\mathrm{N}$ storage in this area.

\section{Materials and Methods}

\subsection{Study area}

This study was conducted in the Hulun Buir grassland of Inner Mongolia, China $\left(47^{\circ} 05^{\prime}-53^{\circ} 20^{\prime} \mathrm{N}, 115^{\circ} 31^{\prime}-\right.$ $126^{\circ} 04^{\prime} \mathrm{E}$ ) (Fig. 1), which is located in the western part of Da Hinggan Mountains with a relatively flat topography ranging from $650-700 \mathrm{~m}$ above sea level. The mean annual precipitation and temperature are $339 \mathrm{~mm}$

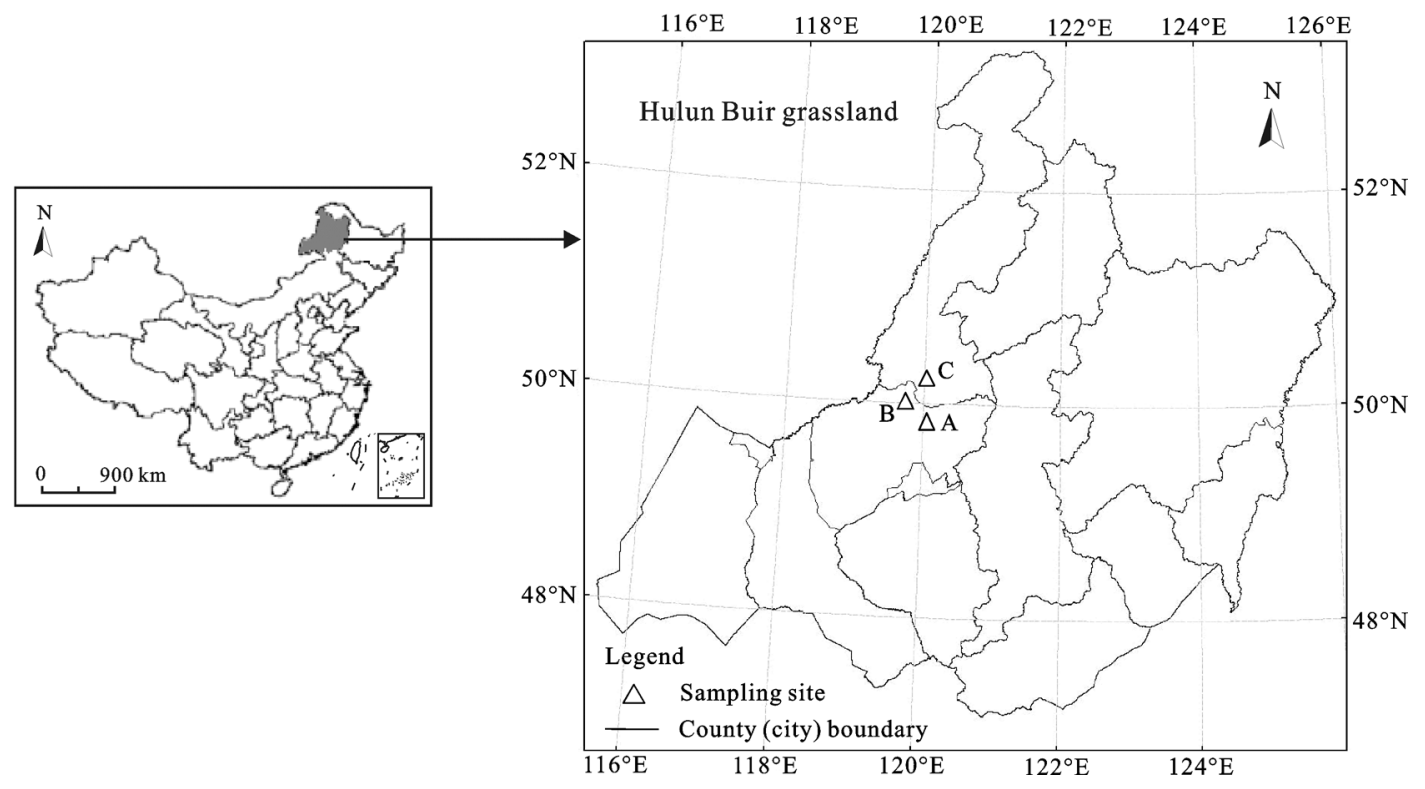

Fig. 1 Location of study area and sampling sites 
and $-2.2^{\circ} \mathrm{C}$, respectively. Edaphic characteristics (physical traits and chemical nutrition) are heterogeneous and the main soil types are chernozem and chestnut in the study area (Liu et al., 2010; Wu et al., 2013). Gradually decreasing precipitation from east to west results in floristically distinct land cover types in this region, including arid steppe (dominated by Allium polyrhizum), typical steppe (dominated by Serratula centauroides, Salsola collina, Chenopodium glaucum and Carex korshinskyii) and meadow steppe (dominated by Leymus chinensis, Stipa baicalensis and Carex korshinskyii) (Liu et al., 2010).

\subsection{Field sampling and laboratory analysis}

We established three experiment sites in meadow steppe with similar soil type, plant species and land use history within the Hulun Buir grassland (Fig. 1). At each site, one paired long-term free grazing plot and adjacent grazing exclusion plot were selected. The area of each plot was about 1.0 ha and the distance between plots in each site ranged approximately $100-200 \mathrm{~m}$. The grazing exclusion plots were fenced since 2005 at all three sites due to the RGLG program. The dominated species at three sampling sites are Leymus chinensis and some sedge species (e.g., Carex pediformis). Vegetation measurements and soil sampling were carried out in August 2011, which is a typical period of peak aboveground biomass. In each plot, 5 sampling quadrats $(1 \mathrm{~m} \times$ $1 \mathrm{~m})$ were established at a $15-\mathrm{m}$ interval along a random transect. The aboveground biomass in these quadrats was determined by clipping the plants at ground level, drying at $60^{\circ} \mathrm{C}$ for $48 \mathrm{~h}$, and weighting. Then, aboveground biomass of all plant community was divided into four different functional types: gramineous species, sedge species, leguminous species and forbs species. The belowground biomass was determined by sampling $5 \mathrm{~cm}$ diameter soil cores to a depth of $30 \mathrm{~cm}$ (five sampling points for each quadrat), passing through a 2-mm sieve, washing by water, drying at $60^{\circ} \mathrm{C}$ for $48 \mathrm{~h}$, and weighting.

Soil samples were collected by using a soil sampler (4 cm diameter) at 4 depths: 0-10, 10-20, 20-30 and 30-40 cm. A composite soil sample was obtained for each depth using the soil collected at 3 sampling points within each quadrat. Therefore, within each experimental plot, 5 composite soil samples were collected for each soil depth, yielding a total of 120 composite soil samples for all plots and depths. All the samples were air-dried at room temperature and hand-sieved through a $0.2-\mathrm{mm}$ sieve to remove roots and other debris before determination of the SOC and TN concentrations. Soil bulk density was measured by using the soil cores (100 $\mathrm{cm}^{3}$ volume) obtained from the 4 depths, with 5 replicates for each plot. These measurements of bulk density at different depths were used to estimate the mass of SOC and TN at each plot. The $\mathrm{pH}$ of $0-10 \mathrm{~cm}$ soil samples were measured in a $1: 2.5$ water suspension.

The organic $\mathrm{C}$ concentrations in soil samples were determined by using the Walkley-Black dichromate oxidation procedure (Nelson and Sommers, 1982). The soil TN concentrations were measured using the modified Kjeldahl wet digestion procedure (Gallaher et al., 1976). Then the total SOC storage (TSOC) and total soil nitrogen storage (TSN) were calculated according to the method of He et al. (2008) on a ground area basis up to a 40-cm depth as follows:

TSOC $=\sum_{i=1}^{4} D_{i} \times P_{i} \times O M_{i}$

$T S N=\sum_{i=1}^{4} D_{i} \times P_{i} \times T N_{i}$

where TSOC and TSN are the total soil $\mathrm{C}$ and $\mathrm{N}$ storage, respectively; $D_{i}$ is the soil thickness of the $i$ th soil depth (cm); $P_{i}$ is the soil bulk density of the $i$ th soil depth $\left(\mathrm{g} / \mathrm{cm}^{3}\right) ; O M_{i}$ and $T N_{i}$ are the soil organic $\mathrm{C}$ and TN concentrations (\%) of the $i$ th soil depth, respectively. In this study, $i=1,2,3$, and 4 .

\subsection{Statistical analyses}

Statistical analyses were carried out with SPSS 13.0 and SigmaPlot 2000 (SPSS Inc., Chicago, USA). All data were expressed as mean \pm stand error (SE) of mean. An analysis of variance (ANOVA) was used to evaluate the effect of grazing exclusion on soil $\mathrm{C}$ and $\mathrm{N}$ storage. Correlations between soil variables were calculated using Pearson coefficient. Regression analyses were used to assess the relationship between aboveground biomass and soil $\mathrm{C}$ and $\mathrm{N}$ storage.

\section{Results}

\subsection{Effects of grazing exclusion on vegetation and soil properties}

The effects of grazing exclusion on vegetation charac- 
teristics and soil bulk density are presented in Table 1. The aboveground biomass in grazing exclusion plots was significantly higher than that in long-term grazing plots at all three sites $(p<0.05)$. In grazing plot at site $\mathrm{B}$, aboveground biomass was only $24.09 \pm 6.10 \mathrm{~g} / \mathrm{cm}^{2}$, which was more than 3 times lower as compared to the grazing exclusion plot at the same site. At all three sites, aboveground biomass of gramineous and sedge species were significantly increased by grazing exclusion $(p<0.05$, Table 2). However, in most instances, grazing exclusion had no remarkable effect on the aboveground biomass of leguminous and forbs species. Removal of grazing significantly increased belowground biomass at site $\mathrm{C}$ $(p<0.05$, Table 1$)$. However, there were no significant differences of belowground biomass between grazing and exclosure plots at site A and B. Meanwhile, the 6-year grazing exclusion also altered soil properties in this meadow steppe (Table 1). Fencing the grasslands generally resulted in a decrease of soil bulk density and $\mathrm{pH}$, but statistical difference of bulk density $(p<0.05)$ was only showed by the soils from site A.

\subsection{Effects of grazing exclusion on soil organic carbon and total nitrogen}

In both grazing and exclosure plots at all three sites, soil $\mathrm{TN}$ and SOC concentrations were generally significantly declining with soil depth increase (Figs. 2 and 3). At sites $\mathrm{A}$ and $\mathrm{C}$, grazing exclusion significantly increased
SOC concentrations along the soil profile up to a $20-\mathrm{cm}$ depth $(p<0.05)$. However, removal of grazing only increased SOC content significantly at $0-10 \mathrm{~cm}$ depth for soils in site B (Fig. 2). Totally, similar trends were also observed for soil TN concentration (Fig. 3). At 0-20 cm depth, soil TN concentrations were significantly higher in grazing exclusion plot than in long-term grazing plot for all three sites. Although the grazing exclusion plots generally have higher soil TN concentrations than grazing plots when depth is higher than $20 \mathrm{~cm}$, the differences were not statistically significant $(p>0.05)$.

The SOC storage in soil profile of $0-40 \mathrm{~cm}$ in grazing exclusion plots was $75.29 \pm 1.50 \mathrm{Mg} \mathrm{C} / \mathrm{ha}$, which was about $13.9 \%$ higher than that in long-term grazing plots $(p<0.01)$. However, this significant difference of SOC storage was mainly existed in the $0-30 \mathrm{~cm}$ soil depth (Fig. 4a). Additionally, grazing exclusion also significantly increased the soil TN storage in soil profile of $0-40 \mathrm{~cm}(p<0.01$, Fig. $4 \mathrm{~b})$. These results suggested that grazing exclusion had the potential to sequester $\mathrm{C}$ and $\mathrm{N}$ in soils, but short-term (6-year) grazing exclusion might resulted in a higher $\mathrm{C}$ and $\mathrm{N}$ sequestration potential in the upper soil.

\subsection{Relationships among SOC, TN, C/N and aboveground biomass}

Significant positive correlations between the contents of soil TN and SOC were observed in both grazing exclu-

Table 1 Characteristics of three experimental sites (Mean \pm SE)

\begin{tabular}{|c|c|c|c|c|c|c|c|}
\hline $\begin{array}{l}\text { Sampling } \\
\text { site }\end{array}$ & Dominant species & Soil type & Treatment & $\begin{array}{c}\mathrm{BD} \\
\left(\mathrm{g} / \mathrm{cm}^{3}\right)\end{array}$ & $\mathrm{pH}$ & $\begin{array}{c}\text { Aboveground } \\
\text { biomass }\left(\mathrm{g} / \mathrm{cm}^{2}\right)\end{array}$ & $\begin{array}{c}\text { Belowground } \\
\text { biomass }\left(\mathrm{g} / \mathrm{cm}^{2}\right)\end{array}$ \\
\hline \multirow{2}{*}{ Site A } & Leymus chinensis & \multirow{2}{*}{ Chernozem } & Long-term grazing & $1.17^{*}$ & $7.1 \pm 0.1$ & $45.10 \pm 6.82$ & $1095.13 \pm 167.64$ \\
\hline & Carex pediformis & & Exclosure since 2005 & 1.11 & $7.0 \pm 0.1$ & $115.56 \pm 8.85^{* *}$ & $1328.71 \pm 196.20$ \\
\hline \multirow{2}{*}{ Site B } & \multirow{2}{*}{ Leymus chinensis } & \multirow{2}{*}{ Chernozem } & Long-term grazing & 1.20 & $7.3 \pm 0.2$ & $24.09 \pm 6.10$ & $891.11 \pm 157.63$ \\
\hline & & & Exclosure since 2005 & 1.18 & $7.1 \pm 0.1$ & $86.84 \pm 4.74^{* *}$ & $1248.61 \pm 228.09$ \\
\hline \multirow{2}{*}{ Site C } & \multirow{2}{*}{ Leymus chinensis } & \multirow{2}{*}{ Chernozem } & Long-term grazing & 1.19 & $7.2 \pm 0.1$ & $31.00 \pm 4.94$ & $1153.02 \pm 158.32$ \\
\hline & & & Exclosure since 2005 & 1.16 & $7.1 \pm 0.1$ & $107.71 \pm 8.64^{* *}$ & $1475.26 \pm 36.35^{*}$ \\
\hline
\end{tabular}

Notes: BD: Bulk density of $0-10 \mathrm{~cm}$ soil depth. The locations of sampling sites A, B and C were shown in Fig. $1 . *: p<0.05 ; * *: p<0.01$

Table 2 Aboveground biomass of different functional types under grazing and exclosure treatments in different sampling sites $\left(\mathrm{g} / \mathrm{cm}^{2}\right)$

\begin{tabular}{|c|c|c|c|c|c|c|}
\hline \multirow{2}{*}{ Functional type } & \multicolumn{2}{|c|}{ Site A } & \multicolumn{2}{|c|}{ Site B } & \multicolumn{2}{|c|}{ Site C } \\
\hline & Grazing & Exclosure & Grazing & Exclosure & Grazing & Exclosure \\
\hline Gramineous species & 21.7 & $80.5^{* *}$ & 18.1 & $69.2^{* *}$ & 17.8 & $85.3^{* *}$ \\
\hline Sedge species & 13.8 & $21.2^{* *}$ & 3.2 & $10.6^{* *}$ & 5.3 & $12.1^{* *}$ \\
\hline Leguminous species & 2.3 & $7.8^{* *}$ & 1.1 & 3.2 & 3.0 & 4.3 \\
\hline Forbs species & 7.3 & 6.1 & 1.7 & 2.8 & 4.9 & 6.0 \\
\hline
\end{tabular}

Note: $* *$ indicates $p<0.01$ 


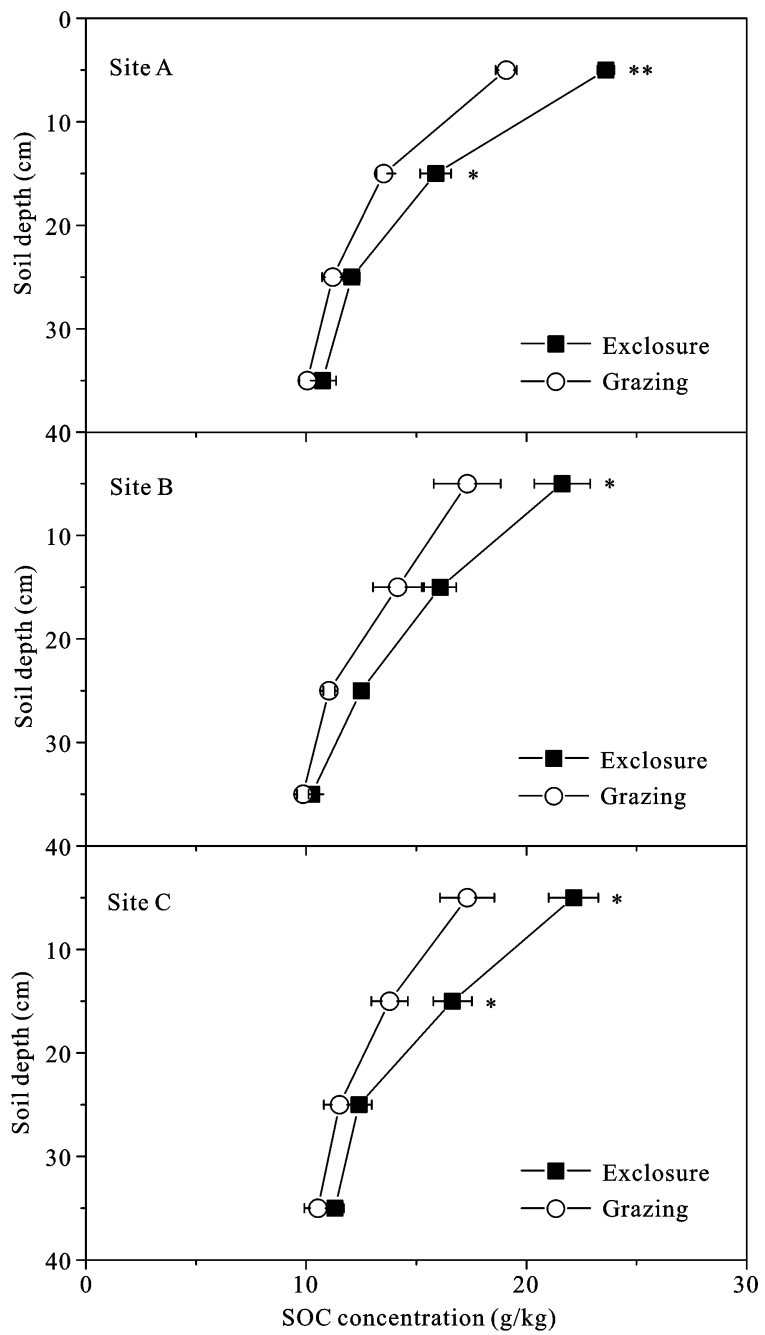

Fig. 2 Effects of grazing exclusion on soil organic carbon (SOC) concentrations along soil profile in different sampling sites. Error bars are the standard error of mean. *: $p<0.05 ; * *: p<0.01$

sion and long-term grazing plots $(p<0.01$, Table 3$)$. The soil $\mathrm{C} / \mathrm{N}$ ratios were generally positively correlated with SOC $(p<0.01)$, but have weak correlations with soil TN contents. Moreover, the relationship between aboveground biomass and SOC storage exhibited significant linear relationship at $0-30 \mathrm{~cm}$ soil depths $(p<0.01)$ (Fig. 5). Similarly, aboveground biomass was significantly correlated with soil TN storage within upper 0-30 cm soil depths.

\section{Discussion}

\subsection{Effects of grazing exclusion on vegetation and soil properties}

Our study showed that the 6-year grazing exclusion had resulted in a significant recovery in vegetation with higher aboveground biomass, but a lower soil bulk density and $\mathrm{pH}$ value, which are consistent with earlier researches (Wu et al., 2009; Chen et al., 2012). The reduced perturbation had a direct effect on the aboveground biomass, demonstrating that grazing exclusion is an effective practice to improve vegetation productivity in degraded grassland (Tanentzap et al., 2009; Zhou et al., 2011). The substantial increase of aboveground biomass in our study sites was mainly due to the significant recovery of gramineous and sedge species after grazing exclusion, which is in agreement with other studies (Wu et al., 2009). Moreover, grazing exclusion decreased the proportion of forbs species aboveground biomass in our meadow steppe sites, indicating that grazing exclusion practice in the RGLG program had

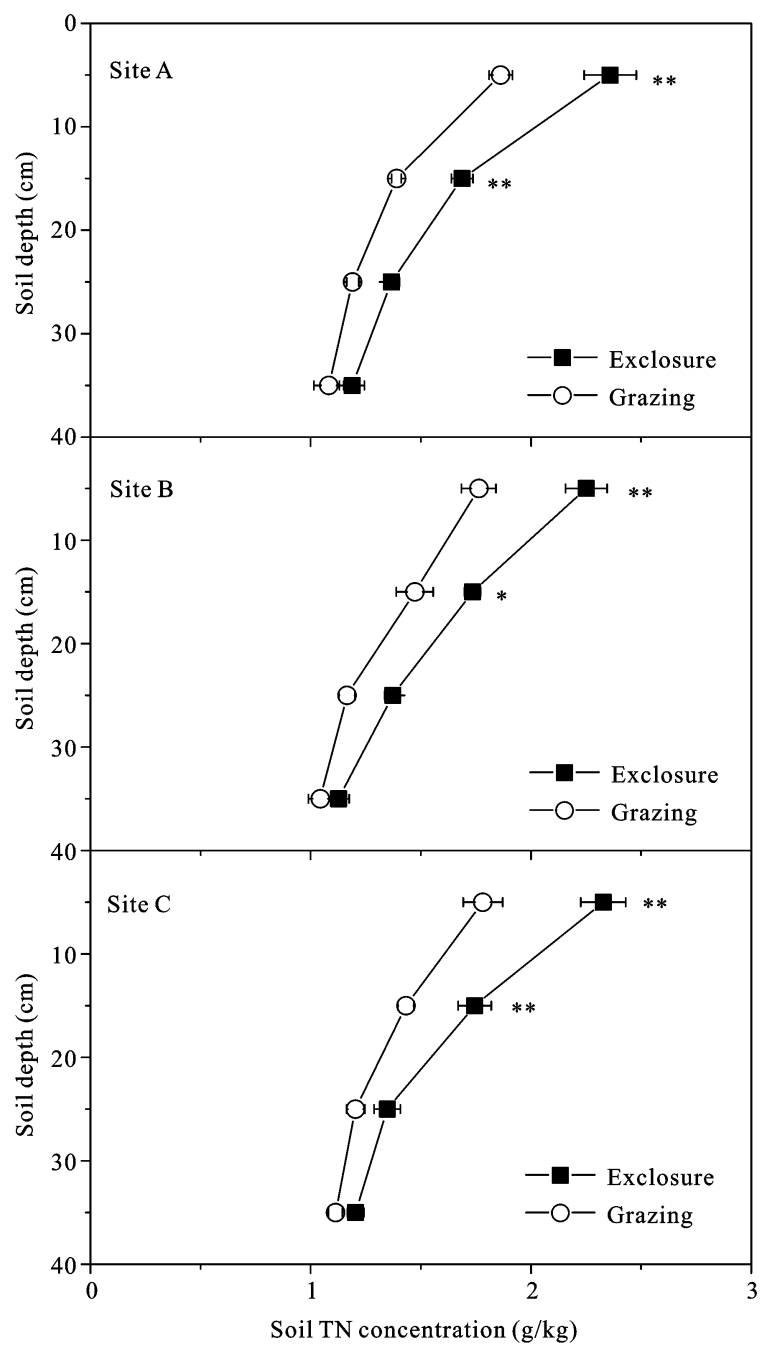

Fig. 3 Effects of grazing exclusion on soil TN concentrations along soil profile in different sampling sites. Error bars are the standard error of the mean. $*: p<0.05 ; * *: p<0.01$ 

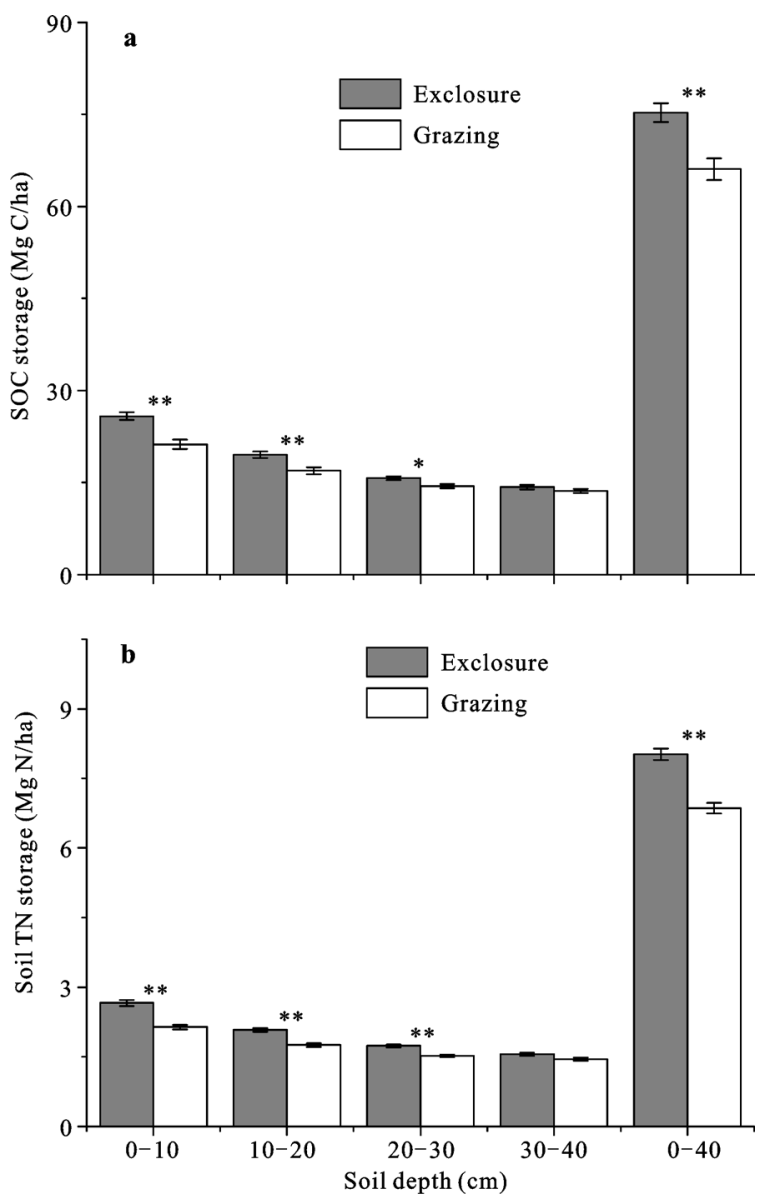

Fig. 4 Effects of grazing exclusion on SOC (a) and TN (b) storage in different soil depths of grasslands. Error bars are the standard error of mean. $*: p<0.05 ; * *: p<0.01$

Table 3 Correlation coefficients between SOC, TN and $\mathrm{C} / \mathrm{N}$ for different treatments (incorporating all depths, $N=60$ )

\begin{tabular}{cccl}
\hline Treatment & Parameter & TN & C/N \\
\hline \multirow{2}{*}{ Grazing } & SOC & $0.934^{* *}$ & $0.487^{* *}$ \\
& TN & & 0.152 \\
\multirow{2}{*}{ Exclosure } & SOC & $0.959^{* *}$ & $0.409^{* *}$ \\
& TN & & 0.148 \\
\hline
\end{tabular}

advantages for restoring degraded grassland in this area. Besides the aboveground biomass, removal of grazing also resulted in an increase of belowground biomass at our three experiment sites, which is consistent with other studies (Cheng et al., 2011; Qiu et al., 2013). However, some studies reported that grazing exclusion had insignificant or even negative effects on belowground biomass (Reeder et al., 2004; Niu et al., 2011). The inconsistency of these results might be due to complicated factors, such as the degree of degrada- tion before grazing exclusion, the soil and vegetation types, the duration of grazing exclusion and the regional climatic conditions (Pineiro et al., 2009; Wu et al., 2009; Cheng et al., 2011). The lower soil bulk density after grazing exclusion might mainly due to the reduced trampling by livestock (Su et al., 2005).

SOC and TN storage in long-term free grazing plots are approximately $66.1 \mathrm{Mg} \mathrm{C} / \mathrm{ha}$ and $6.9 \mathrm{Mg} \mathrm{N} / \mathrm{ha}$, respectively, which are similar to values previously reported for medium degradation grasslands in Inner Mongolia (He et al., 2008; Liu et al., 2012). A 6-year grazing exclusion, as shown by this study, could increase the SOC and TN storage by $13.9 \%$ and $17.1 \%$, respectively, in the $0-40 \mathrm{~cm}$ soil depth. By summarying 133 papers on the impacts of management and land use change on soil carbon in the northern China's grasslands, Wang et al. (2011) found that exclosure of degraded grassland from grazing can significantly increase soil carbon content. Several potential mechanisms could be the reasons for the increased SOC and TN storage in the enclosed grasslands. Firstly, in the present study aboveground biomass was found to have a significantly positive correlation with SOC and TN storage in the upper soil (Fig. 5), suggesting that the higher SOC and TN storage in grazing exclusion plots could be partly attributed to the increased aboveground biomass. As grazing exclusion reduced the outflow of energy and nutrient from soil-plant system to livestock, the input of $\mathrm{C}$ and $\mathrm{N}$ into soils could be increased. Secondly, the increased belowground biomass might be another possible explanation for the accumulation of $\mathrm{C}$ and $\mathrm{N}$ in soils, since plant root residues are the primary source of soil organic matters (Reeder et al., 2004). Thirdly, the decreased loss of $\mathrm{C}$ and $\mathrm{N}$ from soils could also lead to the accumulation of SOC and TN after grazing exclusion. Because grazing is known to simulate soil mineralization, nitrification and ammonification, which in turn resulted in higher soil respiration rates and $\mathrm{N}_{2} \mathrm{O}$ emissions (Polley et al., 2008; Giese et al., 2013). These losses of SOC and TN are thought to be reduced when the disturbance is stopped by grazing exclusion (Qiu et al., 2013).

Although our results show that grazing exclusion significantly increased both concentration and storage of SOC and TN in semi-arid grasslands, the existing literature contains many inconsistent results. Several researchers have found significant increase of SOC and 


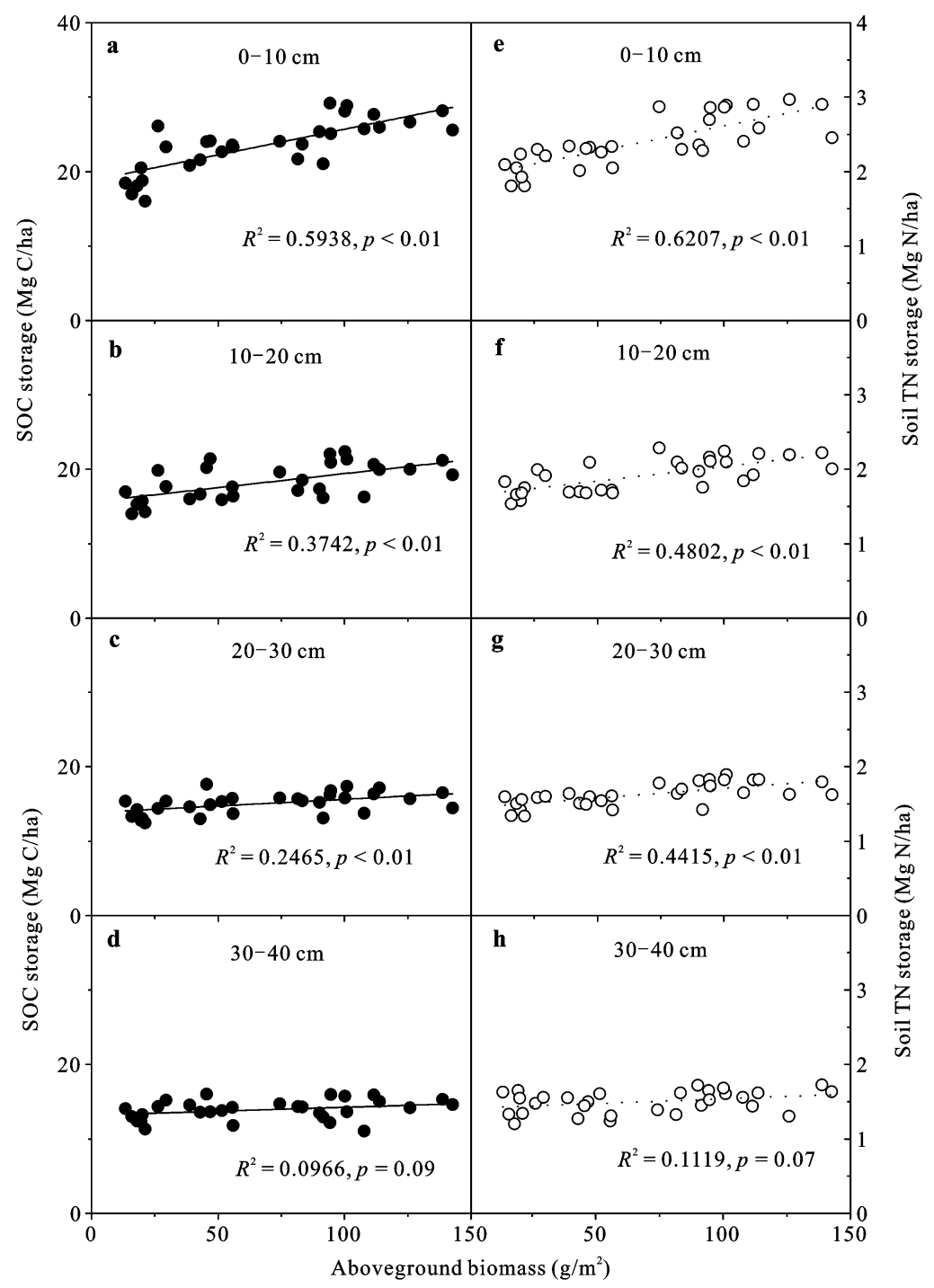

Fig. 5 Relationship between aboveground biomass and SOC (a, b, c, d) and TN (e, f, g, h) storages in different soil depths of grasslands

TN storages in response to grazing exclusion ( $\mathrm{Su}$ et al., 2005; Wu et al., 2009; Zhou et al., 2011), whereas others reported that grazed sites exhibited higher SOC and TN storages or without statistically significantly difference compared with adjacent no grazed sites (Reeder $e t$ al., 2004; Shrestha and Stahl, 2008; Liu et al., 2012). These differences may partly due to whether grazing pressure exceeds carrying capacity of a site and whether it is sufficiently far beyond that capacity to reach the ecological threshold (Sasaki et al., 2011). Additionally, the discrepancies in duration of exclosure, climatic conditions, original and post-grazing vegetation, soil properties from different studies were also found to be the causes for the inconsistent results (Reeder et al., 2004; Chen et al., 2012; Medina-Roldan et al., 2012).

\subsection{Implications for grazing exclusion within RGLG program}

The effect of grazing on changes in SOC and TN storages in semi-arid grassland has received much attention, but the accumulation of SOC and TN after grazing exclusion has rarely been reported, especially for the RGLG program. In our study, the grazing exclusion resulted in an increase of SOC and TN at the rates of $1.5 \mathrm{Mg} \mathrm{C} /($ ha $\cdot y r)$ and $0.19 \mathrm{Mg} \mathrm{N} /($ ha $\cdot y r)$, respectively. These values are greater than the estimated global SOC sequestration rate of grassland (Lal, 2004), suggesting that grazing exclusion may accelerate the sequestration of SOC, at least in semi-arid grassland. Although our results demonstrated a high potential for grazing exclusion to increase SOC and TN storages, it would need 
decades to fully restore this degraded grassland to a stable or mature state as reported by He et al. (2008). Because several studies have indicated that after an initial rapid increase following grazing exclusion, the sequestration rate generally decreased with duration of exclusion (Zhou et al., 2011; Qiu et al., 2013). However, our estimates might underestimate the actual sequestration potential, since we did not include the $\mathrm{C}$ and $\mathrm{N}$ gain from biomass and litter accumulation, or consider the contribution of atmospheric deposition to the $\mathrm{C}$ and $\mathrm{N}$ increase. If these factors were to be included into estimates, the effect of grazing exclusion on $\mathrm{C}$ and $\mathrm{N}$ storage could become more significant (Chen et al., 2012). It is therefore necessary to comprehensively evaluate the effect of grazing exclusion on ecosystem $\mathrm{C}$ and $\mathrm{N}$ storage in this region after the implementation of the RGLG program. Moreover, our study only analyzed the changes of SOC and TN storage after 6 years of grazing exclusion within the RGLG program. Thus, it is essential to conduct more long-term studies in order to determine the changes in $\mathrm{C}$ and $\mathrm{N}$ allocation in the ecosystem with increasing exclosure duration and evaluate the effectiveness of the RGLG program for restoring degraded grasslands. Additionally, future conservation practices within the RGLG program should include both economic and biological considerations, since $\mathrm{C}$ and $\mathrm{N}$ storage through grazing exclusion might have a relatively lower trade off with the present implementation costs (Wang et al., 2011).

\section{Conclusions}

Our results showed that the degraded grasslands in $\mathrm{Hu}-$ lun Buir grassland of Inner Monglia, China appear to be recovering and exhibiting high potential to sequester $\mathrm{C}$ and $\mathrm{N}$ after the removal of grazing. Grazing exclusion for 6 years resulted in significant increases of above and below-ground biomass, SOC and TN contents and storages. The accumulation of SOC and TN after exclusion of livestock could be partly explained by decreased loss and increased input of $\mathrm{C}$ and $\mathrm{N}$ to soils. The effects of grazing exclusion on $\mathrm{SOC}$ and $\mathrm{TN}$ concentration and storage primarily occurred in the upper soil depths. Therefore, it is apparent from this study that grazing exclusion within the RGLG program is an effective restoration approach to control grassland degradation. These findings are potentially important because more than $6.0 \times 10^{7}$ ha degraded grasslands are included in the nationwide RGLG program. Thus, more long-term studies have to be carried out for different vegetation types and exclosure duration under different climatic conditions, and to enhance the comprehensive multidisciplinary researches for better grassland management strategies.

\section{References}

Chen Y, Li Y, Zhao X et al., 2012. Effects of grazing exclusion on soil properties and on ecosystem carbon and nitrogen storage in a sandy rangeland of Inner Mongolia, Northern China. Environmental Management, 50(4): 622-632. doi: 10.1007/ s00267-012-9919-1

Chen Zuozhong, Wang Shiping, 2000. Typical Steppe Ecosystem of China. Beijing: Science Press, 305-309. (in Chinese)

Cheng J, Wu G, Zhao L et al., 2011. Cumulative effects of 20year exclusion of livestock grazing on above- and belowground biomass of typical steppe communities in arid areas of the Loess Plateau, China. Plant Soil and Environment, 57(1): 40-44.

Cui X, Wang Y, Niu H et al., 2005. Effect of long-term grazing on soil organic carbon content in semiarid steppes in Inner Mongolia. Ecological Research, 20(5): 519-527. doi: 10.1007/ s11284-005-0063-8

Follett R F, Reed D A, 2010. Soil carbon sequestration in grazing lands: Societal benefits and policy implications. Rangeland Ecology \& Management, 63(1): 4-15. doi: 10.2111/08-225.1

Gallaher R N, Weldon C O, Boswell F C, 1976. A semiautomated procedure for total nitrogen in plant and soil samples. Soil Science Society of America Journal, 40(6): 887-889.

Giese M, Brueck H, Gao Y Z et al., 2013. N balance and cycling of Inner Mongolia typical steppe: A comprehensive case study of grazing effects. Ecological Monographs, 83(2): 195-219. doi: 10.1890/12-0114.1

He N, Han X, Yu G et al., 2011. Divergent changes in plant community composition under 3-decade grazing exclusion in continental steppe. PLoS ONE, 6(11): e26506. doi: 10.1371/ journal.pone.0026506

$\mathrm{He} \mathrm{N}, \mathrm{Yu} \mathrm{Q}, \mathrm{Wu} \mathrm{L}$ et al., 2008. Carbon and nitrogen store and storage potential as affected by land-use in a Leymus chinensis grassland of northern China. Soil Biology \& Biochemistry, 40(12): 2952-2959. doi: 10.1016/j.soilbio.2008.08.018

Klumpp K, Fontaine S, Attard E et al., 2009. Grazing triggers soil carbon loss by altering plant roots and their control on soil microbial community. Journal of Ecology, 97(5): 876-885. doi: 10.1111/j.1365-2745.2009.01549.x

Lal R, 2004. Soil carbon sequestration impacts on global climate change and food security. Science, 304(5677): 1623-1627. doi: 10.1126/science.1097396

Liu N, Zhang Y, Chang S et al., 2012. Impact of grazing on soil carbon and microbial biomass in typical steppe and desert 
steppe of Inner Mongolia. PLoS ONE, 7(5): e36434. doi: 10.1371/journal.pone.0036434

Liu Yong, Wang Cheng, Yue Wenze et al., 2013. Storage and density of soil organic carbon in urban topsoil of hilly cities: A case study of Chongqing Municipality of China. Chinese Geographical Science, 23(1): 26-34. doi: 10.1007/s11769-0130585-x

Liu Z, Fu B, Zheng X et al., 2010. Plant biomass, soil water content and soil N:P ratio regulating soil microbial functional diversity in a temperate steppe: A regional scale study. Soil Biology \& Biochemistry, 42(3): 445-450. doi: 10.1016/j.soilbio. 2009.11.027

Mcsherry M E, Ritchie M E, 2013. Effects of grazing on grassland soil carbon: A global review. Global Change Biology, 19(5): 1347-1357. doi: 10.1111/gcb.12144

Medina-Roldan E, Paz-Ferreiro J, Bardgett R D, 2012. Grazing exclusion affects soil and plant communities, but has no impact on soil carbon storage in an upland grassland. Agriculture, Ecosystems and Environment, 149(3): 118-123. doi: 10.1016/j.agee.2011.12.012

Nelson D W, Sommers L E, 1982. Total carbon, organic carbon, and organic matter. In: Page A L (eds.). Methods of Soil Analysis. Part 2: Chemical and Microbial Properties. Madison: American Society of Agronomy, 539-552.

Ni J, 2002. Carbon storage in grasslands of China. Journal of Arid Environments, 50(2): 205-218. doi: 10.1006/jare.2201. 0902

Niu D, Hall S J, Fu H et al., 2011. Grazing exclusion alters ecosystem carbon pools in Alxa desert steppe. New Zealand Journal of Agricultural Research, 54(3): 127-142. doi: 10.1080/ 00288233.2011 .576683

Pineiro G, Paruelo J M, Jobbagy E G et al., 2009. Grazing effects on belowground $\mathrm{C}$ and $\mathrm{N}$ stocks along a network of cattle exclosures in temperate and subtropical grasslands of South America. Global Biogeochemical Cycles, 23: GB2003. doi: 10.1029/2007GB003168

Polley H W, Frank A B, Sanabria J et al., 2008. Interannual variability in carbon dioxide fluxes and flux-climate relationships on grazed and ungrazed northern mixed-grass prairie. Global Change Biology, 14(7): 1620-1632. doi: 10.1111/j.1365-2486. 2008.01599.x

Qiu L, Wei X, Zhang X et al., 2013. Ecosystem carbon and nitrogen accumulation after grazing exclusion in semiarid grassland. PLoS ONE, 8(1): e55433. doi:10.1371/journal.pone.
0055433

Reeder J D, Schuman G E, Morgan J A et al., 2004. Response of organic and inorganic carbon and nitrogen to long-term grazing of the shortgrass steppe. Environmental Management, 33(4): 485-495. doi: 10.1007/s00267-003-9106-5

Sasaki T, Okubo S, Okayasu T et al., 2011. Indicator species and functional groups as predictors of proximity to ecological thresholds in Mongolian rangelands. Plant Ecology, 212(2): 327-342. doi: 10.1007/s11258-010-9825-7

Shrestha G, Stahl P D, 2008. Carbon accumulation and storage in semi-arid sagebrush steppe: Effects of long-term grazing exclusion. Agriculture, Ecosystems and Environment, 125(1-4): 173-181. doi: 10.1016/j.agee.2007.12.007

Su Y, Li Y, Cui J et al., 2005. Influence of continuous grazing and livestock exclusion on soil properties in a degraded sandy grassland, Inner Mongolia, northern China. Catena, 59(3): 267-278. doi: 10.1016/j.catena.2004.09.001

Tanentzap A J, Burrows L E, Lee W G et al., 2009. Landscape-level vegetation recovery from herbivory: progress after four decades of invasive red deer control. Journal of Applied Ecology, 46(5): 1064-1072. doi: 10.1111/j.1365-2664.2009. 01683.x

Wang S, Wilkes A, Zhang Z et al., 2011. Management and land use change effects on soil carbon in northern China's grasslands: A synthesis. Agriculture, Ecosystems and Environment, 142(3-4): 329-340. doi: 10.1016/j.agee.2011.06.002

Wu G, Du G, Liu Z et al., 2009. Effect of fencing and grazing on a Kobresia-dominated meadow in the Qinghai-Tibetan Plateau. Plant and Soil, 319(1-2): 115-126. doi: 10.1007/s11104008-9854-3

Wu X, Liu G, Butterbach-Bahl K et al., 2013. Effects of land cover and soil properties on denitrification potential in soils of two semi-arid grasslands in Inner Mongolia, China. Journal of Arid Environments, 92(5): 98-101. doi: 10.1016/j.jaridenv. 2013.02.003

Wu X, Yao Z, Brüggemann N et al., 2010. Effects of soil moisture and temperature on $\mathrm{CO}_{2}$ and $\mathrm{CH}_{4}$ soil-atmosphere exchange of various land use/cover types in a semi-arid grassland in Inner Mongolia, China. Soil Biology \& Biochemistry, 42(5): 773-787. doi: 10.1016/j.soilbio.2010.01.013

Zhou Z, Li F, Chen S et al., 2011. Dynamics of vegetation and soil carbon and nitrogen accumulation over 26 years under controlled grazing in a desert shrubland. Plant and Soil, 341(1-2): 257-268. doi: 10.1007/s11104-010-0641-6 